\title{
La responsabilidad civil de los árbitros en el Ecuador: hacia la regulación de un ámbito no explorado
}

\author{
Javier Jaramillo Troya* \\ Recibido/Received: 15/08/2017 \\ Aceptado/Accepted: 18/08/2017
}

SUMARIO: 1. Introducción. 2. Naturaleza de la responsabilidad de los árbitros. 2.1 La naturaleza extracontractual de la responsabilidad de los árbitros. 2.2 La naturaleza contractual de la responsabilidad de los árbitros. 2.2.1 Generalidades sobre el contrato de receptum arbitri. 2.2.2 Perfeccionamiento del contrato de receptum arbitri. 2.2.3 Contenido obligacional y efectos del contrato de receptum arbitri. 3. La extensión de la responsabilidad de los árbitros. 3.1 La inmunidad de los árbitros. 3.2 La responsabilidad limitada de los árbitros. 3.3 La responsabilidad común de los árbitros. 4. La responsabilidad de los árbitros en el ordenamiento jurídico ecuatoriano. 4.1 ¿Inmunidad arbitral en el Ecuador? 4.2 ¿Responsabilidad limitada o común? 5. Conclusiones.

PALABRAS CLAVE: Responsabilidad, Árbitros, Receptum Arbitri, Inmunidad.

KEYWORDS: Liability, Arbitrators, Receptum Arbitri, Immunity.

\footnotetext{
Asociado en Pérez Bustamante \& Ponce Abogados y Profesor de Arbitraje y Litigación Oral en la Universidad San Francisco de Quito, Secretario Arbitral CAM-CCQ y CIAM. Especialista Superior en MASC por la Universidad Andina Simón Bolívar y Máster en Derecho por la Universidad de Harvard (Dean's Scholar Prize Arbitraje Internacional). Admitido a la práctica en Ecuador y el Estado de Nueva York.

J. JARAmillo Troya, "La responsabilidad civil de los árbitros en el Ecuador: hacia la regulación de un ámbito no explorado", Revista Ecuatoriana de Arbitraje, No. 8, 2016.
} 
RESUMEN: El presente es un estudio sobre la responsabilidad civil de los árbitros en el Ecuador. Tras un análisis de doctrina y jurisprudencia local e internacional este artículo concluye que, bajo el ordenamiento jurídico ecuatoriano, la responsabilidad de los árbitros tiene naturaleza contractual en relación con el contrato de receptum arbitri y se limita al estándar de culpa leve determinado en el Código Civil ecuatoriano.

ABSTRACT: This is a study of arbitrator's liability under Ecuadorian law. By means of analyzing local and international doctrine and case law, this article concludes that in application of Ecuadorian law, arbitrators are liable for breach of the receptum arbitri contract under the negligence standard of liability.

\section{INTRODUCCIÓN}

Recientemente tribunales ordinarios alrededor del mundo han conocido acciones propuestas por partes dentro de un proceso arbitral en contra de uno o varios árbitros del tribunal arbitral por responsabilidad civil derivada de actuaciones jurídicas de ellos dentro del proceso arbitral.

Este fenómeno ha abierto la puerta de discusión en relación con un tema poco explorado en el arbitraje y que tiene mucha relevancia respecto de la legitimidad de la institución teniendo en cuenta que, su piedra angular, se desarrolla sobre la base de una jurisdicción de tipo excepcional por la que, en virtud de la decisión particular de dos o más privados, estos renuncian a la jurisdicción natural de los jueces estatales ordinarios y encargan a uno o más terceros la resolución de una disputa privada mediante lo que la doctrina ha denominado el contrato de receptum arbitri.

En este sentido, al igual que en cualquier contrato, el incumplimiento de cualquiera de las partes genera responsabilidad de 
tipo civil. Por ello, parece claro que, ante un incumplimiento de los árbitros a las obligaciones adquiridas mediante ese vínculo contractual, estos puedan estar sujetos a responsabilidad civil.

Sin embargo, esta aseveración parece no ser tan pacífica en la doctrina y jurisprudencia. La controversia radica, principalmente, en la falta de regulación o, en su defecto, falta de uniformidad, de las distintas legislaciones arbitrales al tratar el tema de responsabilidad de los árbitros.

Por ejemplo, existen legislaciones que, sin negar la necesidad de regular la responsabilidad de los árbitros, debaten acerca de su naturaleza, sin llegar a un consenso sobre si esta debe enancarse en la responsabilidad civil contractual o extracontractual.

Adicionalmente, por una parte, un sector de la doctrina se ha manifestado a favor de la extensión de inmunidad -en distinta medida- hacia los árbitros. Por otro, ciertas legislaciones han negado la inmunidad hacia los árbitros respecto de su actuación dentro de un proceso arbitral, pero han establecido un estándar poco estricto de gradación de responsabilidad, limitándola a casos de errores manifiestos. Finalmente, otras legislaciones, como la ecuatoriana, se han remitido, de manera expresa o tácita, al régimen general de responsabilidad contractual.

Este artículo pretende desarrollar las diferentes tendencias doctrinarias y jurisprudenciales al respecto para aterrizar respecto de la institución de la responsabilidad civil de los árbitros y su aplicabilidad bajo el ordenamiento jurídico ecuatoriano.

Para ello, este estudio se dividirá en tres partes. En la primera de ellas se abordará la naturaleza que, en criterio del autor, tiene la responsabilidad civil de los árbitros. En esta sección se determinará el carácter contractual o extracontractual de la responsabilidad que pueden tener los árbitros en el ejercicio de sus funciones. 
La segunda sección ofrecerá un análisis de la extensión de la responsabilidad aplicable a los árbitros por su actividad dentro de un proceso arbitral. Para ello, este estudio abordará un análisis comparado y se referirá a la doctrina y jurisprudencia que han abordado el tema.

Finalmente, este artículo se referirá a la institución de la responsabilidad civil aplicable a los árbitros en el Ecuador; determinando como, en el caso de ser aplicable, debe ser entendida y tratada bajo el ordenamiento jurídico ecuatoriano.

\section{Naturaleza de la Responsabilidad DE LOS ÁRBITROS}

En el Derecho comparado se ha discutido fervientemente acerca de la naturaleza de la responsabilidad civil de los árbitros. La disquisición se centra en determinar si dicha naturaleza es contractual o extracontractual.

Esta distinción tiene fundamento en la tradición jurídica del país que se trate. Así, por ejemplo, las legislaciones de países del derecho anglosajón o common law caracterizan a la responsabilidad de los árbitros como extracontractual basada en la figura del tort, enfocándola como una violación de los árbitros al deber de cuidado -duty of care- que tienen como profesionales frente a las partes dentro de un proceso arbitral ${ }^{1}$.

Por otro lado, los países de tradición romano-germánica o civil law, así como los países islámicos establecen la responsabilidad de los árbitros y la enfocan desde una naturaleza contractual, considerando al contrato de receptum arbitri como la base para determinar cualquier incumplimiento ${ }^{2}$.

1. Véase, S. Franck, The Liability of International Arbitrators: A Comparative Analysis and Proposal for Qualified Immunity, 20 N.Y.L. Sch. J. Int'1 \& Comp. L, 2000, p. 4.

2. Véase, ibídem. 
Finalmente, MusTILL y BoYD señalan que resulta irrelevante la fuente de responsabilidad de los árbitros considerando que esta depende, exclusivamente, de los deberes específicos de los árbitros que, en su criterio, son: (i) actuar con cuidado; (ii) proceder diligentemente; $y$, (iii) actuar imparcialmente ${ }^{3}$.

\subsection{La naturaleza extracontractual de la responsabilidad de los árbitros}

La tendencia doctrinaria que caracteriza a la responsabilidad de los árbitros como extracontractual tiene como fundamento que, bajo el common law, los profesionales tienen, para con las personas a las que prestan un servicio, un deber de cuidado que, de ser violentado, constituye el tort de negligence.

Esta corriente, que tiene aplicación práctica en Estados Unidos e Inglaterra, considera que todos los profesionales en el ejercicio de su profesión tienen el deber de obrar con la destreza y el cuidado que con el que obraría un profesional diligente en la misma rama en las mismas circunstancias ${ }^{4}$. En ese sentido, bajo esta tesis, los árbitros, como profesionales, tienen un deber de obrar competentemente en su capacidad de terceros dirimentes de una disputa y deben ser responsables por todos los daños generados como resultado de una violación de su deber de cuidado $^{5}$.

Como puede observarse, la caracterización de extracontractual de la responsabilidad de los árbitros bajo el common law tiene como fundamento que, bajo esa tradición jurídica, la responsabilidad de los profesionales está regulada expresamente bajo la institución jurídica de los torts, lo que, en nuestro criterio, no significa que no exista un vínculo contractual entre el profesional

3. Véase, M. J. Mustill y S. C. Boyd, Law and Practice of Commercial Arbitration in England, 2da Ed., 1989, pp. 224-232

4. Véase, W. Prosser y W. Page Keeton, Prosser \& Keeton on The Law Of Torts, 5ta Ed., 1984, pp. 185-188.

5. Véase, A REDFERn y M. Hunter, Law and Practice of International Commercial Arbitration, 2da Ed., 1991, pp. 266, 270. 
y el cliente, sino que, simplemente, los estados del common law han tomado un camino específico respecto de la responsabilidad de los profesionales.

Sin embargo, incluso en países de tradición civil law como es el caso de Alemania, es posible que la responsabilidad de los árbitros sea determinada por la vía extracontractual en los supuestos que no se encuentren reflejados, expresamente, en el contrato de receptum arbitri ${ }^{6}$. Así mismo, en países islámicos como Arabia Saudita parece aceptarse la responsabilidad de los árbitros desde una naturaleza extracontractual si se considera que la normativa, establece, de manera general, que "el árbitro es responsable por cualquier falta cometida que resulte en daño para cualquiera de las partes" ${ }^{\prime 7}$.

\subsection{La naturaleza contractual de la responsabilidad de los árbitros}

\subsubsection{Generalidades sobre el contrato de RECEPTUM ARBITRI}

Como fue referido, el sector mayoritario de la doctrina considera que la responsabilidad de los árbitros tiene como base jurídica un vínculo contractual entre las partes y los árbitros al que se ha denominado contrato de receptum arbitri.

$\mathrm{Al}$ respecto como señala BERGER: "el contrato de receptum arbitri es, esencialmente, un acuerdo del árbitro [o los árbitros] para servir como tal de conformidad con el convenio arbitral celebrado por las partes y crea un contrato entre el árbitro [o los árbitros] y las partes". El contrato de receptum arbitri es, entonces, un contrato bilateral y atípico celebrado entre las partes litigiosas -como una sola parte- y el árbitro.

Aunque es claro que las partes y los árbitros podrían celebrar expresamente este contrato e incluir cláusulas que rijan su relación contractual, la realidad es que son excepcionales los casos en

6. Véase, J. LEW, The Immunity of Arbitrators, Julian E.M, Lew ed., 1990, p. 31.

7. A. HAMID EL-AHDAB, Arbitration with the Arab Countries, pp. 221-22, 348-349.

8. K. P. BERGER, International Economic Arbitration, 1993, p. 232. 
los que esta situación ocurre9 . Es por ello que el contrato de receptum arbitri es considerado un contrato "satélite" que pese a no tener una existencia expresa regula la relación entre los árbitros y las partes de manera implícita ${ }^{10}$.

Por lo anterior, la doctrina no ha sido pacífica al determinar la naturaleza y efectos del contrato de receptum arbitri que ha sido categorizado como un contrato sui generis de cuasi mandato por el que cada árbitro, habiendo aceptado su designación actúa por las dos partes resolviendo su disputa con efectos obligatorios ${ }^{11}$. La doctrina ha considerado que ese contrato de cuasi mandato debe ser caracterizado como uno de servicios y no de obra en el sentido de que los árbitros se obligan a prestar un servicio de conformidad con su conocimiento, esfuerzo y destreza, es decir, a una obligación de medio y no de resultado ${ }^{12}$.

Discrepamos con esta caracterización, puesto que, en nuestro criterio, el contrato de receptum arbitri, si algo, contiene una obligación de resultado por parte de los árbitros de proferir un laudo válido y ejecutable salvo en casos excepcionales en los que, por existir un "tribunal truncado", el cumplimiento de dicha obligación sea eximido.

\subsubsection{Perfeccionamiento del contrato de RECEPTUM ARBITRI}

En cuanto al nacimiento a la vida jurídica o perfeccionamiento del contrato de receptum arbitri, dado que, como se ha mencionado, no es común que las partes y los árbitros redacten un contrato que regule su relación y lo firmen, es importante determinar el momento en que el contrato de receptum arbitri comienza a surtir efectos jurídicos.

9. Véase, S. FrancK, N. 1, p. 6.

10. M. Domke, “The arbitrator's immunity from liability: a comparative survey", U. Tol. Law Review. 1971, p. 101

11. Ídem, p. 100.

12. Véase, S. Franck, N. 1, p. 69. 
La primera parte del consentimiento se encuentra en el convenio arbitral en el que ambas deciden someter a la decisión de uno o más árbitros la controversia existente entre ambos. Este consentimiento puede ser preciso si en el convenio arbitral se señala la identidad de los árbitros -lo cual es poco común- o abstracto si las partes establecen un método de selección de árbitros o se someten a un arbitraje administrado por el cual, el reglamento del centro de arbitraje, establece la forma de seleccionarlos.

El perfeccionamiento del consentimiento por parte de los árbitros se da cuando de manera expresa o tácita aceptan su designación. Al respecto, es importante señalar que la aceptación de los árbitros tiene efecto sobre las dos partes inclusive en los casos de "árbitros de parte" seleccionados únicamente por una de las partes ${ }^{13}$. Esto, por cuanto su designación, incluso de ser realizada únicamente por una de las partes, tiene como base un acuerdo de ambas establecido en el convenio arbitral.

\subsubsection{Contenido obligacional y efectos del contrato de RECEPTUM ARBITRI}

Para poder determinar el alcance de la responsabilidad contractual de los árbitros es importante dilucidar el alcance de sus obligaciones bajo el contrato de receptum arbitri.

$\mathrm{Al}$ respecto, es claro que si las partes han celebrado de manera expresa el contrato de receptum arbitri, el alcance de una posible responsabilidad deberá circunscribirse a las obligaciones pactadas en dicho contrato.

Sin embargo, como se ha mencionado anteriormente, son excepcionales los casos en los que las partes celebran expresamente el contrato de receptum arbitri. Así, ante la falta de un contrato expreso que regule las obligaciones de los árbitros y las partes, parece natural entender que el convenio arbitral celebrado entre 
ellas sea la base para determinar el contenido obligacional del contrato de receptum arbitri.

Así, por ejemplo, las cortes estadounidenses ${ }^{14}$ han establecido que el acuerdo arbitral constituye la base contractual para la autoridad, facultades y responsabilidad de los árbitros

$\mathrm{Al}$ respecto, y de manera preliminar, es importante distinguir entre el convenio arbitral y el contrato de receptum arbitri, puesto que, el primero, si bien puede constituir la base para determinar el contenido obligacional del contrato de receptum arbitri, es un contrato bilateral que, con base en el principio res inter alios acta, surte efectos únicamente respecto de las partes celebrantes, esto es, las partes que deciden someter su disputa a conocimiento de los árbitros.

Así, en el convenio arbitral existen obligaciones netamente bilaterales entre las partes como es el caso de las declaraciones que les obligan a acudir a arbitraje y les prohíben acudir a la justicia ordinaria ${ }^{15}$-kompetenz kompetenz- o que las obligan a acatar el laudo de manera definitiva.

Sin embargo, en el convenio arbitral también existen disposiciones que constituyen ofertas o declaraciones unilaterales de voluntad -considerando a ambas partes del convenio arbitral como una de las partes del contrato de receptum arbitri- relacionadas con el futuro contrato de receptum arbitri que, al momento de ser aceptadas por el árbitro -mediante su aceptación a la designación como tal-, se convierten en obligaciones jurídicas que, en virtud del principio de pacta sunt servanda, se vuelven ley para las partes -las partes litigiosas y los árbitros-.

Así, por ejemplo, disposiciones en el convenio arbitral estableciendo que el procedimiento arbitral será en derecho, facultando a los árbitros para ordenar medidas cautelares sin el auxilio

14. Véase, In Cort c. American Arbitration Ass'n, 795 F. Supp. 970, 972 (N.O. Ca. 1992).

15. Véase, O. SAntos, Naturaleza de los efectos jurídicos del convenio arbitral, 2015, «https://goo.gl/BDY9uG». Para quien el convenio arbitral no genera obligaciones de hacer y no hacer para las partes sino, únicamente, un derecho potestativo. 
de un juez o determinando que el laudo deberá ser emitido en un determinado plazo, se trasforman en derechos, facultades u obligaciones del contrato de receptum arbitri al momento de aceptación del árbitro de su designación para actuar en el procedimiento arbitral.

Pese a ello, es claro que el contenido del convenio arbitral, difícilmente, puede cubrir todos los efectos que la relación entre las partes y el árbitro, generan. Es por ello que, realizando un ejercicio integrativo del contrato de receptum arbitri, en nuestro criterio, todas aquellas obligaciones de los árbitros establecidas en la lex arbitri-especialmente las relacionadas con la responsabilidad de los árbitros-y las disposiciones estableciendo facultades y deberes de los árbitros en los reglamentos aplicables a los arbitrajes administrados son parte del contrato de receptum arbitri como cláusulas naturales del negocio jurídico ${ }^{16}$.

Adicionalmente, y a falta de disposiciones expresas en la lex arbitri respecto a la responsabilidad contractual de los árbitros, utilizando la misma función integradora antes mencionada, consideramos que las disposiciones del derecho civil común relacionadas a la responsabilidad civil contractual, también formarían parte del contrato de receptum arbitri como cláusulas naturales del negocio jurídico ${ }^{17}$.

Es sobre esta base del contenido obligacional del contrato de receptum arbitri, que consideramos debe evaluarse la responsabilidad de los árbitros desde un punto de vista contractual.

16. Véase, G. Ospina Fernández, Teoría General del Contrato y del Negocio Jurídico, 2005, p. 36. Para quien los elementos naturales del negocio jurídico son aquellos que, aún a falta de estipulación se producen espontáneamente opera legis por encontrarse dentro de la legislación aplicable al contrato.

17. Véase, ibídem. 


\section{LA EXTENSIÓN DE LA RESPONSABILIDAD DE LOS ÁRBITROS}

Independientemente de la fuente que da lugar a la responsabilidad de los árbitros, las distintas corrientes doctrinarias y legislaciones han tomado posiciones diferenciadas respecto a la extensión y límites a la responsabilidad de los árbitros respecto de su actividad dentro de un proceso arbitral.

\subsection{La inmunidad de los árbitros}

La teoría que plantea la inmunidad de los árbitros frente a la responsabilidad respecto de las partes en su actividad dentro de un proceso arbitral tiene origen en los países del common law. Así, uno de los primeros casos sobre la base de los cuales se desarrolló esta teoría es Jones c. Brown ${ }^{18}$. En el caso, el árbitro a cargo del proceso arbitral demandó a las partes con el fin de cobrar sus honorarios por el servicio prestado. Una de las partes del arbitraje reconvino señalando que el Tribunal Arbitral había conspirado para defraudarlo al emitir un laudo en su contra antes de que la evidencia fuere presentada para su conocimiento. La corte rechazó la reconvención respecto del fraude señalando que el árbitro demandado gozaba de inmunidad respecto de cualquier acción de responsabilidad por sus "actos judiciales"19.

Como se desprende de Jones c. Brown la inmunidad de responsabilidad de los árbitros tiene como base su caracterización como "jueces" y de su actividad como "judicial".

Como señala AlESSI, es evidente que esta teoría tiene como base el "estatus" similar o análogo que tienen los árbitros en sus funciones en relación con los jueces, que es, el de administrar jus-

\footnotetext{
18. Véase, M. A. Sponseller, Redefining Arbitral Immunity: A Proposed Qualified Immunity Statute for Arbitrators 44 Hastings L.J. 421,27 1992-1993. Citando Jones c. Brown 6 N.W., p. 141.

19. Véase, Jones c. Brown 6 N.W., p. 143.
} 
ticia $^{20}$. En este sentido, dado que, por vía legal, se ha delegado a los árbitros un "poder del estado", es natural que gocen de inmunidad, sea esta limitada o no, de la misma manera que gozan los jueces que ejercen esta facultad estatal ${ }^{21}$.

La teoría de inmunidad de responsabilidad basada en el "estatus" ha sido compartida por doctrinarios como PIERRE LALIVE, para quien: "(a) las funciones de los árbitros son judiciales o cuasi judiciales; (b) los jueces gozan y deben gozar de inmunidad, y, (c) entonces, los árbitros también deben gozar de inmunidad"22.

Adicionalmente, y como apoyo a la teoría de la inmunidad de los árbitros por responsabilidad derivada de su actuación en un proceso arbitral, se ha señalado la importancia de los árbitros de decidir libremente sin miedos y reservas respecto a una posible acción por responsabilidad. Así, LORD SALMON ha señalado: "rechazo absolutamente aceptar el riesgo de tener que defenderme de una demanda por negligencia, inclusive si tengo la confianza de que no lo he sido. No tengo ambición ni puedo arriesgarme a ser demandado, inclusive en un caso importante" ${ }^{\prime 23}$.

De lo anterior, se desprende, entonces, que la inmunidad de los árbitros es similar a la de los jueces en el common law ${ }^{24}$. Siguiendo esta analogía, la inmunidad de los árbitros aplica respecto de todos los "actos arbitrales" en los que los árbitros ejercen "jurisdicción" realizados en el curso del proceso arbitral ${ }^{25}$.

Adicionalmente, cabe puntualizar que en el common law la inmunidad de responsabilidad de los árbitros se hace extensiva a la institución que administra el arbitraje, de tal manera que, cuando el árbitro adquiera inmunidad, la entidad administradora gozará de este privilegio; por el contrario, si se determina que el

20. Véase, D. ALESSI, Enforcing Arbitrator's Obligations: Rethinking International Commercial Arbitrators' Liability Kluwer Arbitration, p. 4.

21. Véase, ibídem.

22. P. Lalive, "Irresponsibility in International Commercial Arbitration", Asia Pacific Law Review, Vol. 7(2), 1999, p. 66.

23. B. M. CREMADES, "Should arbitrators be immune from liability?", Int'l Fin. Law. Review, 1991, p. 33.

24. Véase, D. R. Nolan y R. I. AbRams, Arbitral Immunity, 11 INDUS. REL. L.J., 1989, p. 237.

25. Véase, ibídem. 
árbitro no tiene inmunidad, la entidad administradora tampoco la tendrá ${ }^{26}$.

Sin embargo, la inmunidad absoluta demostrada en Jones $c$. Brown ha sido moderada por la jurisprudencia estadounidense. Por ejemplo, en el caso Baar c. Tigerman la Corte de Apelaciones de California negó el carácter absoluto de la inmunidad de los árbitros y, por lo mismo, negó la inmunidad al árbitro Tigerman que, en la visión de la Corte, había violado el contrato - de receptum arbitri- al no proferir el laudo a tiempo ${ }^{27}$.

En el caso, el árbitro Tigerman no emitió el laudo en el término establecido por las Reglas de Arbitraje de la AAA -American Arbitration Association-; de hecho, después de que trascurrieron siete meses desde el cierre de la instrucción, Tigerman no había proferido el laudo. Las partes demandaron al árbitro y a la AAA por incumplimiento de contrato ${ }^{28}$.

La corte de instancia rechazó la demanda sobre la base de la inmunidad de los árbitros. La Corte de Apelaciones de California revirtió el fallo distinguiendo que, los casos de inmunidad de responsabilidad de los árbitros citados por la corte de instancia, se referían a violaciones en la decisión tomada por los árbitros en contraste con el caso actual en el que, en la visión de la Corte, la alegación se refería a una violación contractual de un deber básico del árbitro Tigerman ${ }^{29}$.

En nuestro criterio, la decisión en Baar c. Tigerman es un interesante avance que, además de poner en tela de duda la inmunidad ilimitada de los árbitros, abandona la tesis del "estatus" antes mencionada y se enfoca en el contrato de receptum arbitri como fuente para determinar la responsabilidad de los árbitros.

Adicionalmente, la teoría de la inmunidad ilimitada de los árbitros basada en su "estatus" ha recibido fuertes críticas. Prin-

26. Véase, M. A. Sponseller, N. 18, p. 428.

27. Véase, ibídem.

28. Véase, Corte de Apelaciones, Baar c. Tigerman, 189 Cal. Rptr, 1983, p. 839.

29. Véase, ibídem. 
cipalmente, estas se enfocan en poner en tela de duda el silogismo planteado por Lalive para sustentar la inmunidad de los árbitros.

La crítica se fundamenta en que la analogía entre jueces y árbitros es impropia, por cuanto los árbitros no son jueces. Así, los detractores a la teoría del "estatus" y la inmunidad de los árbitros realizan las siguientes distinciones entre ambas calidades: (i) las funciones y facultades de los árbitros son creadas por las partes y no por el estado; (ii) los árbitros no crean jurisprudencia obligatoria y tampoco están obligados a acatarla; (iii) los laudos arbitrales tiene un ámbito mucho más limitado de revisión que las decisiones judiciales; (iv) a diferencia de los jueces, los árbitros tienen la posibilidad de declinar su designación o negociar sus términos ${ }^{30}$.

A lo anterior podemos acotar que: v) a diferencia de los jueces los árbitros no tienen la facultad intrínseca de imperium para mediante el uso de la fuerza ejecutar sus decisiones, $y$, finalmente, (vi) los jueces no reciben un estipendio como honorario profesional por la prestación del servicio en cada caso específico pagado por las partes, ni pueden negociarlo.

\subsection{La responsabilidad limitada de los árbitros}

Las referidas críticas a la teoría de inmunidad ilimitada de la responsabilidad de los árbitros respecto de su actividad dentro de un proceso arbitral, han provocado la evolución legislativa y jurisprudencial -especialmente en países del civil law- que ha desarrollado un estándar de responsabilidad limitada de los árbitros.

Esta tendencia ha sido desarrollada principalmente por los países de tradición romano-germánica, en un intento de garantizar la libertad de los árbitros para decidir; sin que, dicha libertad, sea óbice para que, en casos limitados, los árbitros sean responsables por su actuación dentro de un proceso arbitral ${ }^{31}$.

30. Véase, D. Alessi, N. 20, p. 5.

31. Véase, B. M. Cremades, N. 23, p. 34. 
Por esta razón, algunos países del civil law han limitado legislativamente la responsabilidad de los árbitros a casos de dolo o negligencia inexcusable $e^{32}$. Esta limitación parece coincidir con que, en los países de tradición romano-germánica, no es posible excluir contractualmente este tipo de responsabilidad mediante contrato o, como se conoce en el Ecuador ${ }^{33}$, condonar el dolo futuro.

Así, como ejemplo de conductas por parte de árbitros dentro de un proceso arbitral que podrían considerarse dolosas o con negligencia inexcusable podríamos mencionar (i) emitir el laudo fuera de término; (ii) violación de normas o principios procesales que resulten en violación del derecho a la defensa de las partes; (iii) violación a los principios de contradicción e igualdad procesal; (iv) vicios de incongruencia en el laudo, (v) emitir un laudo sobre materia inarbitrable, e, inclusive, (vi) violación de la ley aplicable al fondo de la controversia con negligencia e ignorancia inexcusable ${ }^{34}$.

Como ejemplo de legislaciones que han limitado el estándar de gradación para la responsabilidad de los árbitros tenemos la legislación española que, en el artículo 21 de la Ley de Arbitraje, señala:

Artículo 21. Responsabilidad de los árbitros y de las instituciones arbitrales. Provisión de fondos.

1. La aceptación obliga a los árbitros y, en su caso, a la institución arbitral, a cumplir fielmente el encargo, incurriendo, si no lo hicieren, en responsabilidad por los daños y perjuicios que causaren por mala fe, temeridad o dolo. En los arbitrajes encomendados a una institución, el perjudicado tendrá acción directa contra la misma, con independencia de las acciones de resarcimiento que asistan a aquélla contra los árbitros.

Se exigirá a los árbitros o a las instituciones arbitrales en su nombre la contratación de un seguro de responsabilidad civil

32. Véase, ibídem.

33. Véase, Código Civil Ecuatoriano, Art. 1481: El pacto de no pedir más en razón de una cuenta aprobada, no vale en cuanto al dolo contenido en ella, si no se ha condonado expresamente. La condonación del dolo futuro no vale (énfasis añadido)", RO Sup. No. 46, 24/06/2005.

34. Véase, B. M. CRemades, N. 23, p. 34. 
La responsabilidad civil de los árbitros en el Ecuador: hacia la regulación de un ámbito no explorado

o garantía equivalente, en la cuantía que reglamentariamente se establezca. Se exceptúan de la contratación de este seguro o garantía equivalente a las Entidades públicas y a los sistemas arbitrales integrados o dependientes de las Administraciones públicas.

De la norma transcrita, devienen dos elementos claves dentro de la tendencia que establece una responsabilidad limitada de los árbitros, a saber: (i) que la responsabilidad de los árbitros tiene naturaleza contractual con base en el encargo o contrato de receptum arbitri, y, (ii) que el estándar de responsabilidad es restringido, exclusivamente, a casos de dolo, temeridad o mala fe.

Recientemente, la aplicación de esta norma estuvo en juego en la sentencia del Tribunal Supremo español ${ }^{35}$ que condenó a dos árbitros por sus actuaciones en un proceso arbitral.

El caso se refiere a un arbitraje iniciado por Puma AG RD Sport c. Estudio 2000, S.A., el 6 de agosto de 2009. De conformidad con el convenio arbitral y las reglas de arbitraje aplicables, cada parte seleccionó un árbitro y el presidente fue seleccionado de común acuerdo por los árbitros de parte.

Al momento de la deliberación, en una reunión preliminar, el Tribunal Arbitral, discutía respecto de la cantidad que ordenaría fuere pagada como indemnización de daños y perjuicios. De los hechos del caso, se desprende que el Tribunal Arbitral estuvo cerca de llegar a un consenso, pero en una reunión posterior, el árbitro designado por Puma manifestó su oposición al acuerdo sugiriendo una reducción del monto por daños.

Tras la última reunión, el árbitro designado por Puma salió de viaje -hecho conocido por sus co-árbitros- y estos, se reunieron y dictaron un laudo en los términos en los que estaban de acuerdo ambos. El laudo ${ }^{36}$, que fue notificado a las partes sin la firma del árbitro designado por Puma, estableció:

35. Tribunal Supremo Español, Sala de lo Civil. Sentencia No. 362/2017.

36. Ibídem. 
[e]ste laudo es firmado, de conformidad con lo dispuesto en el artículo 37.3 de la Ley de Arbitraje, por D. Obdulio y por D. Marcos formando entre ambos la mayoría de los miembros del Colegio Arbitral requerida por el citado artículo. No consta la firma de D. Calixto por no haber prestado aún su conformidad al presente laudo, cuya notificación a las partes se considera no obstante conveniente realizar a la mayor brevedad posible de acuerdo con el interés en tal sentido expresado por las mismas durante el presente arbitraje.

Cabe recalcar que el plazo para dictar el laudo vencía casi dos meses después de que fue proferido.

Tras la expedición del laudo, Puma planteó acción de nulidad. Esta fue aceptada con base en las violaciones a los principios de contradicción y colegialidad del laudo.

Puma inició una acción de responsabilidad civil en contra de los árbitros que dictaron el laudo con base en el artículo 21 de la Ley de Arbitraje española antes transcrita.

El Tribunal Supremo consideró que la actuación de los árbitros que dictaron el laudo alcanzó -y por ende violentó- el alto estándar de responsabilidad impuesto, al constituir una violación flagrante a los principios de contradicción y colegialidad del laudo al obrar "con pleno conocimiento por los demandados de que este último se encontraba de viaje, se reunieron el día 2 de junio siguiente, sin convocar al tercer árbitro" ${ }^{\prime 37}$.

Otras legislaciones, aunque no establecen limitación a la responsabilidad de los árbitros con base en un estándar de gradación menos estricto, limitan la responsabilidad de los árbitros a casos específicos y taxativos establecidos en la ley.

Así, por ejemplo, la legislación rumana señala que los árbitros son responsables por los daños generados a las partes como resultado de: (i) una renuncia injustificada; (ii) no participar, in- 
justificadamente de la decisión o emitir el laudo fuera de tiempo; (iii) violación al principio de confidencialidad; (iv) violación flagrante de sus deberes ${ }^{38}$.

En la misma línea, la legislación italiana ha tipificado tres situaciones en las que un árbitro puede ser declarado responsable frente a las partes por acciones $u$ omisiones durante un proceso arbitral, a saber: (i) dolo o culpa grave en la demora ejerciendo las funciones encomendadas; (ii) renuncia a su designación sin causa justificada; y, (iii) dolo o culpa grave en la omisión de dictar el laudo dentro de los límites establecidos en la normativa aplicable $^{39}$.

\subsection{La responsabilidad común de los árbitros}

A diferencia de lo mencionado en la sección anterior, varios estados no han establecido una gradación menos estricta o limitada para la responsabilidad de los árbitros respecto de sus actividades dentro de un proceso arbitral. Por ello, sea de manera expresa o tácita se han referido al régimen general de responsabilidad civil -contractual en la mayoría de los casos- para regular la responsabilidad de los árbitros.

Austria, por ejemplo, establece en su Código de Procedimiento Civil, de manera general, que los árbitros son responsables por el incumplimiento a cualquiera de sus deberes y obligaciones encargados ${ }^{40}$-mediante el contrato de receptum arbitri-. Así, dependiendo de los límites a la responsabilidad de los árbitros establecidos en el contrato de receptum arbitri, cualquier parte perjudicada puede demandar a los árbitros por daños generados sea por dolo, culpa grave o negligencia simple ${ }^{41}$.

\footnotetext{
38. Véase, P. SANDERS, "National Report on Romanial” en J. PAULsson, International Handbook on Commercial Arbitration, Wolters Kluwer, 1998.

39. P. BERNARdINI, Icca International Handbook on Commercial Arbitration, p. 22.

40. Véase, R. Mullerat y J. Blancht, The Liability of Arbitrators: a Survey of Current Practice, Disp. Resol. Int'l, 2007, p. 110.

41. Véase, S. Franck, N. 1.
} 
Sin embargo, el caso austríaco resulta de mayor interés al considerar que la jurisprudencia ha establecido como conditio sine qua non para que uno o más árbitros sean declarados responsables que la parte demandante haya logrado la nulidad del laudo arbitrall $^{42}$.

Afortunadamente, en la última sentencia del Tribunal Supremo austríaco proferida en marzo de 2016, el Tribunal confirmó que un requisito necesario para determinar la responsabilidad de los árbitros es la nulidad del laudo arbitral, salvo en los casos en los que el árbitro haya incumplido de manera culposa o dolosa con sus obligaciones establecidas en el contrato de receptum arbi$\operatorname{tri}^{43}$.

De manera similar a la legislación austríaca, el Código de Procedimiento Civil y Comercial de Argentina establece la responsabilidad de los árbitros para casos en los que, una vez aceptada su designación, incumplan sus funciones arbitrales ${ }^{44}$.

La aplicación de un régimen general y no limitado de responsabilidad puede provenir de la falta de regulación expresa del estado respecto de la responsabilidad civil de los árbitros que provoca la aplicación del régimen general de responsabilidad contractual en la mayoría de los casos-.

Por ejemplo, en el caso francés, no existe norma o regulación específica que trate la inmunidad o limitación de responsabilidad de los árbitros. Es por ello que, Lew, considera que las partes pueden demandar a los árbitros por incumplimiento de contrato por violación a las obligaciones adquiridas mediante el contrato de receptum arbitrit ${ }^{45}$.

\footnotetext{
42. Véase, R. Mullerat y J. Blancht, N. 40.

43. A. Grill y S. LuKIC, Arbitrators 'Liability: Austrian Supreme Court Reconfirms Strict Standards, Kluwer Arbitration Blog, 2016.

44. Véase, P. SANDERS, “National Report on Argentina”, en J. PAUlsson, International Handbook on Commercial Arbitration, Wolters Kluwer, 1998.

45. Véase, J. LEw, N. 6, p. 17.
} 
En Colombia, dado que no existe un tratamiento expreso respecto de la responsabilidad de los árbitros, la Corte Constitucional ha determinado que los árbitros son responsables penal y civilmente. La Corte señaló que, en aplicación de la legislación local, los árbitros pierden el cincuenta por ciento de sus honorarios por los perjuicios causados a las partes a través del proceso ordinario y por el paso del tiempo, en el cual las partes no ejercen su derecho a la defensa ${ }^{46}$.

Las legislaciones sueca, polaca y suiza son similares a la francesa al respecto ${ }^{47}$, al igual que la ecuatoriana que será estudiada a continuación.

\section{LA RESPONSABILIDAD DE LOS ÁRBITROS EN EL ORDENAMIENTO JURÍDICO ECUATORIANO}

El ordenamiento jurídico ecuatoriano no regula de manera expresa la responsabilidad de los árbitros por sus actos $u$ omisiones durante el proceso arbitral. Es por ello, que resulta de trascendental importancia determinar las implicaciones de esta carencia respecto de: (i) la fuente obligacional que sirve como sustento para determinar la responsabilidad de los árbitros en el Ecuador, y, (ii) la extensión de esa responsabilidad.

En cuanto a la fuente obligacional que sirve como fundamento para entender la responsabilidad de los árbitros en el Ecuador parece claro que esta debe ser contractual.

Esto, por cuanto, no resultaría aplicable la aplicación que hace el common law a la responsabilidad arbitral bajo el tort de negligence porque, bajo la legislación ecuatoriana, la responsabilidad extracontractual deviene, naturalmente, del cometimiento de un delito o cuasidelito civil y excluye, necesariamente, obligaciones de tipo contractual.

46. Véase, Corte Constitucional de Colombia, Sentencia No. C-451/95.

47. Véase, S. FrancK, N. 1, pp. 45-47. 
Dado que en la legislación ecuatoriana no existe norma alguna en el ordenamiento jurídico que regule la responsabilidad arbitral, $y$, tomando en cuenta que la responsabilidad por deficiente prestación de servicios profesionales implica, necesariamente, la consideración de un vínculo contractual -expreso o tácito- entre cliente y profesional, parece resultar ajeno al régimen civil ecuatoriano considerar a la responsabilidad de los árbitros como extracontractual. Parece más armónico, entonces, considerar a la responsabilidad arbitral como contractual bajo el contrato de receptum arbitri antes referido.

La dificultad, entonces, radica en determinar el contenido de este contrato que, a más de atípico, no es comúnmente celebrado entre los árbitros y las partes litigantes ${ }^{48}$. Tal y como fue explicado anteriormente ${ }^{49}$ a falta de un texto expreso que regule las obligaciones entre partes y árbitros, su contenido deberá analizarse en referencia a las disposiciones aplicables del convenio arbitral, la lex arbitri -Ley de Arbitraje y Mediación (LAM)- y, de ser el caso, el reglamento de arbitraje aplicable para arbitrajes administrados.

En relación con la extensión de la responsabilidad de los árbitros en el ejercicio de sus facultades en un proceso arbitral, considerando que el ordenamiento jurídico no trata esta fenomenología y que la fuente obligacional para que tenga lugar la antedicha responsabilidad sería contractual, resulta de importancia analizar el régimen general de responsabilidad contractual para determinar la efectiva extensión de la responsabilidad arbitral en el Ecuador.

\section{1 ¿Inmunidad arbitral en el Ecuador?}

Analizando la legislación ecuatoriana, y, en referencia a la teoría de la inmunidad de los árbitros por su "estatus" cuasi ju-

\footnotetext{
48. Esta aseveración es realizada sobre la base de la experiencia del autor como secretario arbitral en distintos centros de arbitraje locales.

49. Véase, sección 2.2.3.
} 
dicial, parece imposible argumentar la existencia de inmunidad de los árbitros.

Si bien es cierto que podría argumentarse que, considerando que los artículos 7 inciso cuarto y 17 inciso segundo del Código Orgánico de la Función Judicial (COFJ) determinan que los árbitros "ejer[cen] funciones jurisdiccionales" y que el arbitraje "[constituye] una forma de este servicio público", los árbitros podrían asemejarse como funcionarios públicos cuasi judiciales por lo que deberían gozar de inmunidad, esta argumentación, necesariamente, debe fallar.

Esto, por cuanto, en nuestro criterio, pese a que el COFJ determine que los árbitros ejercen funciones jurisdiccionales, es claro que no lo hacen. Ello, por el simple hecho que los árbitros no gozan de la facultad de imperium para ejecutar forzosamente sus decisiones que es un elemento natural a la función jurisdiccional.

Adicionalmente, en nuestro criterio, la mención del COFJ respecto de que los árbitros ejercen una forma de servicio público, no los convierte en servidores públicos de ninguna manera. Resulta manifiesto, que los árbitros no prestan servicios a entidad estatal alguna y no se encuentran regulados por normas dirigidas a servidores públicos.

Sin embargo, incluso de considerar a los árbitros como funcionarios públicos cuasi judiciales equiparables a un juez bajo la legislación ecuatoriana, estos no gozarían de inmunidad de responsabilidad alguna, por la simple razón de que ni siquiera los jueces estatales gozan de este beneficio bajo el ordenamiento jurídico ecuatoriano.

Por el contrario, la Constitución de la República del Ecuador, en su artículo 11 número 9 establece la responsabilidad judicial por repetición, al señalar que: 
El Estado será responsable por detención arbitraria, error judicial, retardo injustificado o inadecuada administración de justicia, violación del derecho a la tutela judicial efectiva, y por las violaciones de los principios y reglas del debido proceso. Cuando una sentencia condenatoria sea reformada o revocada, el Estado reparará a la persona que haya sufrido pena como resultado de tal sentencia $\mathrm{y}$, declarada la responsabilidad por tales actos de servidoras o servidores públicos, administrativos o judiciales, se repetirá en contra de ellos (énfasis añadido).

De lo anterior se desprende que, en aplicación del régimen jurídico ecuatoriano, no resulta posible argumentar la existencia de inmunidad a favor de los árbitros por su actividad dentro de un proceso arbitral.

\section{2 ¿Responsabilidad limitada o común?}

Dado que, como se ha señalado, no existe en el Ecuador disposición expresa regulando la responsabilidad de los árbitros, resulta imperativo analizar las disposiciones generales de responsabilidad contractual en el Ecuador para determinar si opera sobre los árbitros alguna limitación que aminore su responsabilidad por los servicios prestados durante el proceso arbitral.

Es indudable que el contrato de receptum arbitri es bilateral, sinalagmático y reporta beneficios equiparables a ambas partes en su ejecución. Así, las partes ven resuelta una controversia y los árbitros reciben un estipendio por los servicios prestados para dirimir el conflicto.

Por ello, prima facie, parecería aplicable la disposición contenida en el artículo 1563 del Código Civil ecuatoriano que, gradando la responsabilidad contractual, establece:

Art. 1563.- El deudor no es responsable sino de la culpa lata en los contratos que por su naturaleza sólo son útiles al acreedor; es responsable de la leve en los contratos que se hacen para beneficio recíproco de las partes; y de la levísima, en los contratos 
en que el deudor es el único que reporta beneficio (énfasis añadido).

En este sentido, dado que el contrato de receptum arbitri reporta beneficio recíproco para las partes, parecería que los árbitros, únicamente, responderían por culpa leve respecto de sus actos $\mathrm{u}$ omisiones durante un proceso arbitral. La culpa leve se refleja mediante el estándar de cuidado que emplearía una tercera persona en las mismas circunstancias.

Esta situación debe ser contrastada con legislaciones como la española que limitan la responsabilidad de los árbitros a un estándar más estricto como es el caso del dolo o culpa grave, bajo el cual, los árbitros responden únicamente por actos u omisiones de manifiesta culpabilidad.

Sin embargo, podría argumentarse que, ante la falta de regulación de la responsabilidad arbitral en el Ecuador, dada la experticia de los árbitros en su arte $u$ oficio, de conformidad con el principio de lex artis, estos deberían responder bajo un estándar menos estricto de responsabilidad.

Pese a ello, esta idea no encuentra una disposición categórica en la legislación civil ecuatoriana. El Código Civil no incluye en su texto disposición expresa respecto de la responsabilidad civil contractual que utilice el criterio de la lex artis para gradar la responsabilidad civil contractual. Por el contrario, las menciones a la lex artis se encuentran en normas dispersas a lo largo del Código Civil ecuatoriano ${ }^{50}$, por lo cual, no parece pacífico aplicar un estándar más estricto de responsabilidad.

Al respecto, es claro que corresponderá a la jurisprudencia desarrollar qué actos u omisiones de los árbitros dentro de su ac-

50. Véase, i.e. Art. 1798 del Código Civil ecuatoriano: “Art. 1798.- Son vicios redhibitorios los que reúnen las calidades siguientes: 1 . Haber existido al tiempo de la venta; 2 . Ser tales que por ellos la cosa vendida no sirva para su uso natural, o sólo sirva imperfectamente, de manera que sea de presumir que, conociéndolos el comprador, no la hubiere comprado, o la hubiera comprado a mucho menos precio; y, 3. No haberlos manifestado el vendedor, y ser tales que el comprador haya podido ignorarlos sin negligencia grave de su parte, o tales que el comprador no haya podido fácilmente conocerlos en razón de su profesión u oficio (énfasis añadido)", RO Sup. No. 46, 24/06/2005. 
tividad arbitral activan el estándar de culpa leve antes mencionado. Sin embargo, parece pacífico concluir que todas aquellas referidas anteriormente, esto es (i) emitir el laudo fuera de término; (ii) violación de normas o principios procesales que resulten en violación del derecho a la defensa de las partes; (iii) violación a los principios de contradicción e igualdad procesal; (iv) vicios de incongruencia en el laudo; (v) emitir un laudo sobre materia inarbitrable; e, inclusive, (vi) violación de la ley aplicable al fondo de la controversia con negligencia e ignorancia inexcusable $^{51}$, -que han sido catalogadas como violatorias del estándar de culpa grave o dolo bajo la legislación española- alcanzan el estándar de culpa leve.

En ese sentido, realizando un análisis comparativo de las situaciones mencionadas, parece claro que muchas de ellas guardan relación con las causales de nulidad establecidas en el artículo 31 de la LAM. En este sentido, parece evidente que, frente a casos en los que se haya anulado el laudo por una de las mencionadas causales, nos encontraríamos frente a situaciones en las que, bajo la legislación ecuatoriana, los árbitros pudieran ser condenados al pago de daños y perjuicios frente a las partes.

Capítulo aparte merece el estudio respecto a si: (i) la nulidad de laudo constituye prueba suficiente para determinar la responsabilidad de los árbitros; o, (ii) la nulidad -como es en el caso de la legislación austríaca- es un requisito necesario para iniciar una acción de responsabilidad en contra de los árbitros; que, por no ser materia de este estudio preliminar, quedarán postergadas para un análisis futuro.

\section{Conclusiones}

Del análisis trazado a lo largo de este artículo, queda de manifiesto que el tratamiento de la responsabilidad de los árbitros dentro de su actividad en un proceso arbitral no es uniforme y,

51. Véase, N. 23. 
adicionalmente, ha recibido un tratamiento superficial en la mayoría de legislaciones a nivel mundial.

La falta de uniformidad tiene como fundamento, principalmente, la visión diferenciada que tienen al respecto las legislaciones de países de tradición romano-germánica frente a estados del common law.

Esta falta de uniformidad ha provocado divergencias respecto de la fuente obligacional que sirve como base para determinar la responsabilidad arbitral pudiendo ser, según el caso, contractual o extracontractual.

Las divergencias apuntan también a la extensión y limitaciones a la responsabilidad de los árbitros. En ciertos estados, especialmente del common law, los árbitros gozan de inmunidad, razón por la cual, no están sujetos a responsabilidad por su actividad arbitral.

Otras legislaciones -especialmente del civil law-han establecido la responsabilidad de los árbitros, pero la han limitado en un estándar estricto de gradación, por el cual, los árbitros responden, únicamente, por actuaciones que superen el estándar de dolo o culpa grave. Otros estados han limitado la responsabilidad arbitral a situaciones, tipificadas expresamente en el ordenamiento jurídico.

Finalmente, existen estados que regulan la responsabilidad de los árbitros, sea expresamente o mediante reenvió implícito, aplicando el régimen general de responsabilidad contractual que, generalmente, se refiere un estándar menos estricto de responsabilidad por incumplimiento contractual -culpa leve-.

El ordenamiento jurídico ecuatoriano no regula expresamente la responsabilidad de los árbitros. Esta falencia genera dificultades respecto de la determinación de la fuente obligacional aplicable a la responsabilidad de los árbitros y su extensión. 
Este estudio concluye que, en aplicación del ordenamiento jurídico ecuatoriano, la fuente obligacional que sirve de base para determinar la responsabilidad arbitral es el contrato de receptum arbitri. Sin embargo, dada la falta de regulación de este contrato y en consideración a las partes normalmente no lo pactan expresamente, es necesario realizar un ejercicio integrativo para determinar su contenido, recurriendo a la lex arbitri, convenio arbitral y reglas aplicables al arbitraje -en el caso de arbitrajes administrados-.

$\mathrm{Al}$ respecto, concluimos que sería beneficioso que los árbitros, por intermedio de los centros de arbitraje o directamente, de ser el caso, pacten en un documento expreso las disposiciones que regularán la relación contractual entre ellos con el fin de evitar vacíos innecesarios.

Finalmente, respecto de la extensión de la responsabilidad de los árbitros bajo el ordenamiento jurídico ecuatoriano, este estudio concluye que, dada la falta de regulación expresa de esta fenomenología, y, recurriendo al régimen general de responsabilidad contractual, los árbitros responden por sus actos u omisiones por culpa leve.

Sin embargo, este estudio recomienda que, de manera similar a lo realizado en legislaciones de otros países de tradición romano-germánica, la responsabilidad de los árbitros por sus actos $\mathrm{u}$ omisiones dentro de un proceso arbitral sea expresamente regulada en un cuerpo normativo que establezca, de ser el caso, un estándar más estricto de culpabilidad y las particularidades aplicables a la relación jurídica entre los árbitros y las partes litigiosas. 